\title{
ANÁLISE DOS DESFILES DE CARNAVAL DO RIO DE JANEIRO SOB A ÓTICA DO MÉTODO MULTICRITÉRIO LEXICOGRÁFICO
}

Igor Rosa Dias de Jesus ${ }^{1}$ Amurá da Silva Lima Ariane Barbosa Oliveira ${ }^{2}$

Resumo: O presente artigo tem por objetivo a análise dos desfiles das escolas de samba do Carnaval do Rio de Janeiro utilizando o método multicritério lexicográfico. Primeiramente, são feitas algumas considerações sobre os principais métodos multicritério de auxílio à decisão existentes e sobre a estrutura metodológica utilizada para avaliação dos desfiles das escolas de samba do Carnaval carioca. Posteriormente, é apresentada a matriz de decisão do desfile para o ano de 2009, e são verificados os resultados segundo o método oficialmente utilizado no julgamento e segundo uma metodologia alternativa, utilizando o método lexicográfico. $\mathrm{Na}$ conclusão, os resultados obtidos nos dois métodos são comparados e discutidos, permitindo uma maior compreensão sobre o uso do método lexicográfico e o julgamento sobre a viabilidade da sua aplicação para o caso estudado.

Palavras-chave: método lexicográfico, Carnaval, auxílio multicritério à decisão

\begin{abstract}
The purpose of the present article is to analyze the judgment of samba schools parades in Rio de Janeiro's Carnival through the lexicographic multicriteria decision aid method. First, this paper makes some considerations about the main multicriteria decision aid methods and about methodological structure used in the judgment of samba schools parades. Then, the decision matrix for the year 2009 is presented and the results are shown for both ways of judgment: the official one, currently used to rank samba schools; and the alternative one, through the use of lexicographic method. In the conclusion, the results for both methods are discussed and compared, which will allow us a better comprehension about the use of lexicographic method and the judgment about the feasibility of its application for this case.
\end{abstract}

Keywords: lexicographic method, Carnival, multicriteria decision aid

\footnotetext{
1 Universidade Federal Fluminense - UFF e Embrapa.

2 Universidade Federal Fluminense - UFF.
} 


\section{INTRODUÇÃO}

O auxílio multicritério à decisão é uma ferramenta que pode ser aplicada em diversos contextos. Dentre os muitos exemplos possíveis, pode-se citar a utilização do auxílio multicritério à decisão para seleção de empresas tecnológicas para incubação (Oliveira Neto, 2008), para a escolha da geometria de um trem de pouso motorizado (Soares de Mello et al., 2003) e até para decisões a respeito da qualidade da acústica em igrejas (Carvalho, 2008). Dada a variedade de situações em que se faz necessária a tomada de decisão, e que podem ser estruturadas como um problema de decisão multicritério, é natural que emerjam aplicaçôes relativas ao campo do entretenimento. Pode-se dizer que o campo dos esportes vem sendo explorado com bastante ênfase pelos pesquisadores, no que tange à sua problematização através de uma abordagem multicritério (Soares de Mello et al., 2005; Soares de Mello et al., 2001). Estudos recentes como os de Scarf et al. (2009) e Kendall et al. (2010) colaboram para a discussão do uso dos métodos de pesquisa operacional nos esportes, abordando questôes relativas ao método de agendamento das partidas, à forma de ordenação e classificação das equipes, dentre outras. Outras searas no ramo do entretenimento, contudo, têm sido pouco discutidas através deste tipo de análise e a proposta deste trabalho é a de suprir esta lacuna, apresentando uma aplicação das análise multicritério a um conhecido evento brasileiro: ao Carnaval e, de forma específica, ao problema da avaliação das escolas de samba do Rio de Janeiro.

$\mathrm{O}$ artigo será estruturado, portanto, de forma a contextualizar o desfile das escolas de samba em seus diferentes contextos: histórico, econômico, cultural, etc... Naturalmente, será dada ênfase na contextualização do desfile das escolas sob a ótica de seu processo de julgamento, apresentando, dentre outros elementos, o atual método de avaliação.

Posteriormente, será feita uma pequena explanação a respeito da análise multicritério, de forma a conceituar e diferenciar alguns elementos e apresentar quais são os principais métodos que podem ser utilizados para este tipo de análise.

Depois, será realizada a análise do caso dos desfiles das escolas de samba no ano de 2009. Será apresentada a matriz de decisão dos jurados que gerou o resultado da classificação das escolas de samba. Será também apresentado o método lexi- cográfico, bem como as eventuais modificações adaptativas que tenham sido feitas no método, para melhor se adequar ao problema proposto.

Por fim, o método lexicográfico será aplicado à matriz de decisão dos jurados, de forma que será possível analisar e comparar a classificação das escolas de samba segundo o método oficialmente utilizado e segundo a metodologia alternativa proposta.

\section{O CARNAVAL}

Segundo Araújo (2009), há várias origens para a palavra Carnaval, sendo que a versão mais bem aceita é a de que a expressão deriva do latim carrum navalis, em alusão aos carros navais que faziam a abertura das festividades gregas. $\mathrm{O}$ Carnaval é considerado uma das festas populares mais animadas do mundo e remonta a uma festa portuguesa chamada entrudo, na qual as pessoas jogavam uma nas outras, água, ovos e farinha. $\mathrm{O}$ entrudo acontecia num período anterior à quaresma e, portanto, tinha um significado ligado à liberdade. Este sentido permanece até os dias de hoje no Carnaval.

O entrudo chegou ao Brasil por volta do século XVII e foi influenciado pelas festas de caráter carnavalesco que aconteciam na Europa (Leal, 2007). Em países como Itália e França, o carnaval ocorria em formas de desfiles urbanos, onde os carnavalescos usavam máscaras e fantasias. Personagens como a colombina, o pierrô e o Rei Momo também foram incorporados ao carnaval brasileiro, embora sejam de origem européia.

Os primeiros blocos carnavalescos começaram a aparecer no final do século XIX, bem como os cordōes e os famosos "corsos". Estes últimos tornaram-se mais populares no começo do século XX. As pessoas se fantasiavam, decoravam seus carros e, em grupos, desfilavam pelas ruas da cidade. Estes carros, revivendo os carros navais da Grécia Antiga, são os precursores dos carros alegóricos, típicos das escolas de samba atuais.

No século XX, o carnaval foi crescendo e tornando-se cada vez mais uma festa popular. Esse crescimento ocorreu com a ajuda das marchinhas carnavalescas, que deixavam o carnaval mais animado e muito contribuíram para popularizar o carnaval de rua.

O carnaval de rua manteve suas tradições no Nordeste do Brasil. Em cidades como Recife e 
Olinda, as pessoas saem às ruas durante o carnaval no ritmo do frevo e do maracatu, desfilando seus bonecos gigantes (bonecôes). Em Salvador, há trios elétricos, embalados por músicas de cantores e grupos de axé music. Na cidade destacam-se também os blocos negros como o Olodum e o Ileyaê, além dos blocos de rua e do Afoxé Filhos de Gandhi.

No Rio de Janeiro e, posteriormente em São Paulo, o Carnaval evoluiu menos pela vertente do Carnaval de rua e mais pela vertente do espetáculo. Os blocos, então, foram ganhando corpo e tamanho, dando origem às escolas de samba.

Segundo Gomes Júnior \& Gomes (2008), a primeira escola de samba foi fundada no bairro do Estácio em 1928, a Deixa Falar. Em 1932, aconteceu o primeiro desfile extra-oficial e em 1935 ocorreu o primeiro desfile oficial na Praça Onze de Junho, no Rio de Janeiro. A Praça Onze foi destruída e o local do desfile foi alterado diversas vezes. Em 1984, porém, foi construída a Passarela do Samba, local definitivo para o acontecimento dos desfiles. Mais conhecido como Sambódromo, o local foi projetado por Oscar Niemeyer, tem extensão de 700 metros, 85 mil metros quadrados e capacidade para 600 mil pessoas, divididas em vários setores (LIESA, 2009).

Segundo a LIESA (2009), preocupados com o rumo que o desfile das Escolas de Samba seguia, dirigentes de dez das principais agremiaçôes do Rio de Janeiro decidiram se unir e projetar o que pensavam ser o melhor para a festa - e, consequentemente, para o próprio Carnaval carioca. Decidiram, então, em 1984, fundar a Liga Independente das Escolas de Samba do Rio de Janeiro, a LIESA.

Desde então, a LIESA organiza os desfiles das escolas de samba no Sambódromo, bem como é a responsável pelo julgamento das escolas de samba segundo vários quesitos de avaliação. Estes quesitos irão definir qual foi "o melhor desfile do ano” e, consequentemente, a escola campeã.

\section{APOIO MULTICRITÉRIO À DECISÃO}

Roy \& Bouyssou (1993) definem o apoio multicritério à decisão como um conjunto de métodos e técnicas para auxiliar ou apoiar a tomada de decisões, quando da presença de uma multiplicidade de critérios. Estes métodos podem ser classificados como sendo de, basicamente, dois tipos. Os métodos ordinais buscam atender ao problema de ordenação de uma série de variáveis. Este tipo de método não leva em consideração a existência de intervalos entre as posições. Os métodos ordinais consideram apenas a ordenação dos elementos, a criação de um ranking. Os métodos cardinais, em contrapartida, trabalham com o conceito de intervalo (range), tanto em relação às variáveis, quanto em relação aos critérios. Portanto, segundo a lógica cardinal, existe sentido na afirmação de que uma variável "ganhou por pouco" de outra ou de que um critério é "duas vezes mais importante do que o outro".

O presente artigo não pretende se aprofundar em relação aos métodos cardinais. Alguns dos métodos cardinais utilizados no apoio multicritério à decisão são o AHP, o MACBETH e o VIP Analysis. Alguns outros métodos multilticritério de auxílio à decisão também são frequentemente utilizados, dentre os quais podem-se citar o MAUT, o TOPSIS, o PROMETHEE e os métodos da família ELECTRE. Mais informações sobre o método AHP podem ser encontradas em Saaty (1980), sobre o MACBETH em Bana e Costa \& Vansnick (1995), sobre o VIP Analysis em Dias \& Climaco (2000), sobre o MAUT em Abdellaoui \& Gonzales (2010), sobre o TOPSIS em Opricovic \& Tzeng (2004), sobre o PROMETHEE em Brans \& Vincke (1985) e sobre os métodos da família ELECTRE em Figueira et al. (2005)

Quanto aos métodos ordinais, os mesmos são considerados bastante intuitivos e pouco exigentes tanto em termos computacionais quanto em relação às informações necessárias por parte do decisor. Dele não são necessárias mais do que as pré-ordens relativas a cada critério (Barba-Romero e Pomerol, 1997). Os mais conhecidos métodos ordinais são os de Borda, Condorcet e Lexicográfico. Há ainda outros métodos ordinais, como o de Copeland, que nada mais é do que uma variante do método de Condorcet que elimina os ciclos de intransitividade (Gomes Júnior et al., 2008)

O método de Borda, segundo Dias et al. (1996) é, em sua essência, uma soma de postos. Tem a grande vantagem da simplicidade. Para uso deste método, o decisor deve ordenar as alternativas de acordo com as suas preferências; a alternativa preferida recebe um ponto, a segunda, dois pontos, e assim sucessivamente. Os pontos 
atribuídos pelos decisores a cada alternativa são somados, e a alternativa que tiver obtido a menor pontuação é a escolhida. Adaptações do método de Borda são frequentemente utilizadas nos esportes e no entretenimento. A pontuação auferida pelos pilotos nas corridas da Fórmula I são uma adaptação deste método, bem como, segundo Gomes Júnior \& Gomes (2008), o próprio processo de avaliação dos desfiles das escolas de samba.

O método de Condorcet trabalha com relações pareadas entre as variáveis. As mesmas são confrontadas, aos pares, e vê-se qual delas obtém o melhor desempenho e em quantos critérios. É melhor aquela que "vencer" a outra variável em uma maior quantidade de critérios. Segundo Valladares et al. (2008), este método é menos simples que o de Borda e tem a vantagem de impedir distorções ao fazer com que a posição relativa de duas alternativas independa de suas posiçóes relativas a qualquer outra. No entanto, pode conduzir ao chamado "paradoxo de Condorcet" (situaçôes nas quais para três variáveis hipotéticas: "a", "b" e "c", tem-se que "a" ganha de "b"; "b" ganha de "c" e "c" ganha de "a", por exemplo). Essa situação, também conhecida como ciclo de intransitividade, embora possa ser aproveitada em certos problemas, impossibilita gerar uma ordenação das alternativas.

O método lexicográfico é aquele no qual as variáveis são ordenadas segundo o desempenho obtido no critério considerado mais importante pelo decisor. Soares de Mello et al. (2001) explicam que este é o método atualmente utilizado nos Jogos Olímpícos, que constrói o ranking de países baseado primeiramente na quantidade de medalhas de ouro obtidas, passando à contagem das medalhas de prata apenas em caso de empate no número total de medalhas de ouro, e às medalhas de bronze somente em caso de empate entre o número total de medalhas de prata.

Cruz \& Cova (2007) explicam que o método lexicográfico consiste em avaliar todas as alternativas focando-se primeiramente no critério mais importante. A alternativa que ganhar é considerada como sendo a vencedora, ou, se houver empate na $1^{\text {a }}$ colocação, essas alternativas serão encaminhadas sozinhas para o desempate, que será feito com base no próximo critério em importância. Nesse sentido, os critérios menos importantes só serão considerados na medida em que ocorra empate nos critérios mais relevantes. Segundo Soa- res de Mello et al. (2008), este método apresenta duas características fundamentais: assume que o decisor é apto a ordenar cada critério segundo sua importância observada e que o ranking depende do critério considerado como mais importante, independente dos outros critérios.

\section{METODOLOGIA DE AVALIAÇÃO DOS DESFILES}

O método atual de avaliação dos desfiles é através do julgamento por notas, havendo dez quesitos a serem pontuados, cada qual por $4 \mathrm{ju}$ rados, totalizando um total de 40 julgamentos. Segundo a LIESA (2009), cada julgador concederá, para cada escola de samba, notas de sete a dez pontos, esclarecendo-se que:

- serão admitidas as seguintes notas fracionadas em décimos de ponto, ou seja, 7,1 (sete vírgula um) pontos; 7,2 (sete vírgula dois) pontos; 7,3 (sete vírgula três) pontos... até ... 9,9 (nove vírgula nove) e 10,0 (dez) pontos;

- só serão admitidas notas 0 (zero) na hipótese de alguma escola de samba deixar de apresentar o quesito em julgamento;

A LIESA (2009) ressalta que os julgadores estarão avaliando expressões artísticas e, que, por mais que tal avaliação remeta ao campo da subjetividade, os mesmos devem se isentar de emoçôes e de paixóes, exercendo sempre um distanciamento crítico como forma de garantir uma avaliação técnica, com base no entendimento perfeito das diversas partes que integram um quesito no que se refere aos seus critérios de julgamento.

Para facilitar a elaboração da matriz de decisão e seus desdobramentos em outras tabelas no presente trabalho, a cada quesito será atribuída uma abreviação de duas ou três letras. Segundo o Manual do Julgador da LIESA (2009), os quesitos, ou critérios de avaliação, deverão levar em consideração os seguintes fatores:

\section{QUESITO BATERIA (BAT)}

O julgador deverá considerar a manutenção regular e a sustentação da cadência da bateria em consonância com o samba-enredo, a perfeita conjugação dos sons emitidos pelos vários instrumentos e a criatividade e a versatilidade da bateria. 
QUESITO SAMBA-ENREDO (SE)

No quesito samba-enredo, o julgador irá avaliar a letra e a melodia do samba-enredo apresentado, respeitando-se a licença poética.

QUESITO HARMONIA (HAR)

Harmonia é o entrosamento entre o ritmo e o canto.

\section{QUESITO EVOLUÇÃO (EV)}

Evolução é a progressão da dança de acordo com o ritmo do samba que está sendo executado e com a cadência da bateria.

\section{QUESITO ENREDO (ENR)}

Enredo é a criação artística de um tema ou conceito.

\section{QUESITO CONJUNTO (CNJ)}

Conjunto é o "todo" do desfile, ou seja, a forma geral e integrada como a escola de samba se apresenta.

\section{QUESITO ALEGORIAS E ADEREÇOS (A\&A)}

Neste quesito, estão em julgamento as alegorias (entendendo-se, como tal, qualquer elemento cenográfico que esteja sobre rodas) e os adereços (entendendo-se, como tal, qualquer elemento cenográfico que não esteja sobre rodas).

\section{QUESITO FANTASIAS (FAN)}

Neste quesito, estão em julgamento as fantasias apresentadas pela escola de samba, com exceção das que estiverem sobre as alegorias, as fan- tasias do casal de mestre-sala e porta-bandeira e a fantasia da comissão de frente.

\section{QUESITO COMISSÃO DE FRENTE (CF)}

Comissão de frente é o primeiro contingente humano, a pé ou sobre rodas, desde que individualmente, que poderá se apresentar fantasiado, dentro da proposta do enredo ou tradicionalmente.

\section{QUESITO MESTRE-SALA E PORTA- BANDEIRA (MS) \\ O julgador deverá considerar a exibição da dança, a harmonia e a indumentária do casal.}

A escola campeã é definida pela que tiver o maior valor total, dada a soma de todas as 40 notas recebidas pela escola de samba, no que Gomes Júnior e Gomes (2008) definiram como uma variação do método de Borda, onde são definidas pontuações aos critérios e a ordenação final é dada pela ordem decrescente da soma de todas as notas recebidas pelas agremiaçóes, sendo vencedora a escola que obtiver a maior pontuação.

\section{ANÁLISE DE RESULTADOS E TESTE DO MÉTODO LEXICOGRÁFICO}

Neste artigo, será feita a análise dos resultados dos desfiles das escolas de samba no ano de 2009 , de forma que o primeiro passo será apresentar a matriz de decisão e os resultados segundo os métodos oficiais definidos pela LIESA. Os julgamentos e os resultados ocorreram tal como se segue:

Figura 1. Matriz de decisão do desfile das escolas de samba (parte 1)

\begin{tabular}{|c|c|c|c|c|c|c|c|c|c|c|c|c|c|c|c|c|c|c|c|c|}
\hline & \multicolumn{4}{|c|}{ BAT } & \multicolumn{4}{|c|}{ SE } & \multicolumn{4}{|c|}{ HAR } & \multicolumn{4}{|c|}{ EV } & \multicolumn{4}{|c|}{ ENR } \\
\hline & $\begin{array}{l}\frac{-}{0} \\
\frac{0}{0} \\
\frac{\pi}{3} \\
\frac{5}{5}\end{array}$ & $\begin{array}{l}\text { N } \\
\frac{0}{0} \\
\frac{\pi}{3} \\
\frac{\pi}{3}\end{array}$ & $\begin{array}{l}m \\
\frac{0}{0} \\
\frac{\pi}{5} \\
\frac{5}{3}\end{array}$ & $\begin{array}{l}+ \\
\frac{0}{0} \\
\frac{\pi}{5} \\
\frac{5}{3}\end{array}$ & $\begin{array}{l}\frac{1}{0} \\
\frac{0}{0} \\
\frac{\pi}{3} \\
\frac{5}{5}\end{array}$ & $\begin{array}{l}\text { N } \\
\frac{0}{0} \\
\frac{\pi}{3} \\
\frac{\pi}{3}\end{array}$ & $\begin{array}{l}m \\
\frac{0}{0} \\
\frac{\pi}{3} \\
\frac{3}{3}\end{array}$ & $\begin{array}{l}+ \\
\frac{0}{0} \\
\frac{\pi}{5} \\
\frac{5}{5}\end{array}$ & $\begin{array}{l}\frac{-}{\circ} \\
\frac{0}{0} \\
\frac{\pi}{3} \\
\frac{5}{3}\end{array}$ & $\begin{array}{l}\text { N } \\
\frac{0}{0} \\
\frac{\pi}{3} \\
\frac{5}{3}\end{array}$ & $\begin{array}{l}m \\
\frac{0}{0} \\
\frac{\pi}{5} \\
\frac{3}{3}\end{array}$ & $\begin{array}{l}+ \\
\frac{0}{0} \\
\frac{\pi}{3} \\
\frac{7}{5}\end{array}$ & $\begin{array}{l}\overline{0} \\
\frac{0}{0} \\
\frac{\pi}{3}\end{array}$ & $\begin{array}{l}\text { N } \\
\frac{0}{0} \\
\frac{\pi}{3} \\
\frac{5}{3}\end{array}$ & $\begin{array}{l}m \\
\frac{0}{0} \\
\frac{0}{2} \\
\frac{5}{3}\end{array}$ & $\begin{array}{l}+ \\
\frac{0}{0} \\
\frac{\pi}{5} \\
5 \\
5\end{array}$ & $\begin{array}{l}\frac{-}{0} \\
\frac{0}{0} \\
\frac{\pi}{3} \\
\frac{5}{5}\end{array}$ & $\begin{array}{l}\text { N } \\
\frac{0}{0} \\
\frac{\pi}{3} \\
3\end{array}$ & $\begin{array}{l}m \\
\text { 을 } \\
\frac{\pi}{3} \\
\end{array}$ & $\begin{array}{l}+ \\
\frac{0}{0} \\
\frac{\pi}{5} \\
\frac{5}{5}\end{array}$ \\
\hline Império Serrano & 10 & 10 & 10 & 9,9 & 10 & 10 & 10 & 10 & 10 & 9,8 & 9,8 & 9,9 & 9,8 & 9,9 & 9,9 & 9,8 & 9,6 & 9,6 & 9,6 & 9,7 \\
\hline Grande Rio & 10 & 10 & 10 & 9,9 & 10 & 10 & 9,8 & 10 & 10 & 9,9 & 9,9 & 10 & 10 & 9,9 & 10 & 10 & 10 & 9,7 & 9,9 & 10 \\
\hline Vila Isabel & 9,9 & 9,8 & 9,7 & 10 & 9,9 & 9,8 & 9,6 & 9,8 & 10 & 10 & 10 & 10 & 10 & 10 & 10 & 10 & 9,8 & 9,8 & 10 & 10 \\
\hline Mocidade & 9,9 & 10 & 10 & 10 & 9,8 & 9,8 & 9,7 & 9,9 & 9,8 & 9,8 & 10 & 9,8 & 9,7 & 9,9 & 10 & 9,8 & 9,7 & 9,6 & 9,7 & 9,7 \\
\hline Beija-Flor & 10 & 9,9 & 10 & 10 & 10 & 10 & 10 & 10 & 9,9 & 9,9 & 10 & 10 & 10 & 9,8 & 10 & 10 & 9,8 & 9,6 & 9,9 & 9,8 \\
\hline Unidos da Tijuca & 10 & 10 & 9,7 & 9,7 & 9,8 & 10 & 9,7 & 10 & 9,9 & 10 & 10 & 10 & 9,7 & 9,8 & 9,9 & 10 & 9,7 & 9,7 & 9,8 & 9,8 \\
\hline Porto da Pedra & 9,9 & 9,9 & 9,8 & 10 & 9,8 & 9,8 & 9,8 & 9,8 & 9,8 & 9,7 & 9,9 & 9,8 & 9,7 & 9,7 & 9,8 & 9,8 & 9,8 & 9,6 & 9,7 & 9,8 \\
\hline Salgueiro & 10 & 10 & 9,8 & 10 & 10 & 10 & 10 & 10 & 10 & 10 & 9,9 & 10 & 9,9 & 10 & 10 & 10 & 9,8 & 10 & 10 & 9,9 \\
\hline Imperatriz & 10 & 10 & 10 & 9,9 & 10 & 9,7 & 9,8 & 9,8 & 9,9 & 9,9 & 10 & 10 & 10 & 10 & 10 & 10 & 10 & 9,9 & 9,9 & 10 \\
\hline Portela & 9,8 & 10 & 10 & 10 & 10 & 9,9 & 10 & 9,9 & 10 & 10 & 10 & 10 & 10 & 10 & 10 & 10 & 9,8 & 10 & 10 & 9,9 \\
\hline Mangueira & 10 & 9,8 & 10 & 10 & 10 & 10 & 10 & 10 & 10 & 10 & 10 & 9,9 & 9,9 & 10 & 9,8 & 9,9 & 10 & 10 & 10 & 10 \\
\hline Viradouro & 10 & 10 & 10 & 10 & 9,9 & 9,7 & 9,7 & 9,8 & 9,8 & 9,8 & 10 & 9,8 & 9,8 & 9,9 & 10 & 9,8 & 10 & 9,8 & 9,9 & 9,8 \\
\hline
\end{tabular}


Figura 2. Matriz de decisão do desfile das escolas de samba (parte 2)

\begin{tabular}{|c|c|c|c|c|c|c|c|c|c|c|c|c|c|c|c|c|c|c|c|c|}
\hline & \multicolumn{4}{|c|}{ CNJ } & \multicolumn{4}{|c|}{ A\&A } & \multicolumn{4}{|c|}{ FAN } & \multicolumn{4}{|c|}{ CF } & \multicolumn{4}{|c|}{ MS } \\
\hline & 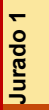 & 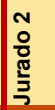 & 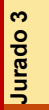 & 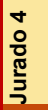 & $\begin{array}{l}\overline{0} \\
\text { o } \\
\frac{\pi}{5} \\
\overline{5}\end{array}$ & 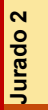 & 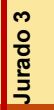 & 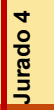 & 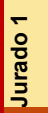 & 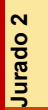 & 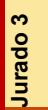 & 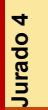 & 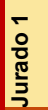 & 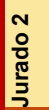 & 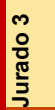 & 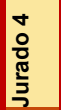 & $\begin{array}{l}\bar{\delta} \\
\frac{5}{\pi} \\
\frac{5}{5}\end{array}$ & 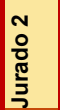 & 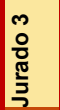 & 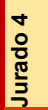 \\
\hline Império Serrano & 9,6 & 9,7 & 9,6 & 9,7 & 9,2 & 9,7 & 9,4 & 9,6 & 9,7 & 9,7 & 9,7 & 9,6 & 9,8 & 9,9 & 9,7 & 9,8 & 9,7 & 9,9 & 9,7 & 9,7 \\
\hline Grande Rio & 10 & 10 & 9,9 & 10 & 9,7 & 9,9 & 9,8 & 9,8 & 9,9 & 10 & 10 & 9,7 & 9,7 & 10 & 9,9 & 9,9 & 9,9 & 10 & 9,9 & 9,9 \\
\hline Vila Isabel & 9,8 & 10 & 10 & 10 & 9,9 & 10 & 10 & 10 & 10 & 10 & 10 & 10 & 10 & 10 & 10 & 10 & 9,8 & 10 & 10 & 10 \\
\hline Mocidade & 9,7 & 9,8 & 9,9 & 9,8 & 9,3 & 9,7 & 9,6 & 9,6 & 9,7 & 9,8 & 9,8 & 9,7 & 9,6 & 9,7 & 9,9 & 9,7 & 10 & 9,9 & 9,9 & 9,8 \\
\hline Beija-Flor & 10 & 10 & 10 & 10 & 9,9 & 10 & 9,9 & 10 & 10 & 10 & 10 & 10 & 10 & 10 & 9,9 & 10 & 9,9 & 10 & 9,9 & 9,9 \\
\hline Unidos da Tijuca & 9,8 & 9,8 & 10 & 9,9 & 9,1 & 9,7 & 9,6 & 9,7 & 9,8 & 10 & 9,9 & 9,6 & 9,8 & 10 & 9,7 & 9,9 & 9,8 & 10 & 10 & 9,8 \\
\hline Porto da Pedra & 9,8 & 9,8 & 9,8 & 9,7 & 9,5 & 9,8 & 9,9 & 9,9 & 9,8 & 9,9 & 9,8 & 9,8 & 9,9 & 9,9 & 9,8 & 9,8 & 10 & 9,9 & 9,9 & 9,9 \\
\hline Salgueiro & 9,9 & 10 & 9,9 & 10 & 10 & 10 & 10 & 10 & 10 & 10 & 10 & 10 & 10 & 10 & 10 & 10 & 9,9 & 10 & 10 & 10 \\
\hline Imperatriz & 9,9 & 9,9 & 9,8 & 9,9 & 9,7 & 9,8 & 9,7 & 9,9 & 10 & 9,9 & 9,9 & 9,8 & 9,8 & 9,9 & 9,9 & 10 & 10 & 10 & 9,9 & 9,9 \\
\hline Portela & 9,9 & 10 & 10 & 10 & 9,8 & 9,9 & 9,8 & 9,7 & 9,9 & 10 & 10 & 9,9 & 10 & 10 & 10 & 9,9 & 10 & 10 & 10 & 9,8 \\
\hline Mangueira & 9,8 & 9,8 & 10 & 9,9 & 9,5 & 9,9 & 9,7 & 9,6 & 9,8 & 10 & 9,9 & 9,8 & 9,9 & 9,9 & 10 & 10 & 10 & 10 & 10 & 10 \\
\hline Viradouro & 9,8 & 9,9 & 10 & 9,7 & 9,6 & 9,9 & 10 & 9,8 & 9,9 & 9,9 & 9,8 & 9,7 & 9,9 & 10 & 10 & 10 & 10 & 9,9 & 9,9 & 9,9 \\
\hline
\end{tabular}

A classificação final das escolas de samba, segundo este método, é obtida pela soma das pontuaçóes obtidas pelas escolas de samba por cada um dos jurados.

Figura 3. Classificação das escolas de samba segundo o método da LIESA

\begin{tabular}{|l|l|r|}
\hline \multicolumn{3}{|c|}{ Classificação } \\
\hline $1^{\circ}$ & Salgueiro & 399,0 \\
\hline $2^{\circ}$ & Beija-Flor & 398,0 \\
\hline $3^{\circ}$ & Portela & 397,9 \\
\hline $4^{\circ}$ & Vila Isabel & 397,6 \\
\hline $5^{\circ}$ & Grande Rio & 396,9 \\
\hline $6^{\circ}$ & Mangueira & 396,8 \\
\hline $7^{\circ}$ & Imperatriz & 396,4 \\
\hline $8^{\circ}$ & Viradouro & 395,1 \\
\hline $9^{\circ}$ & Unidos da Tijuca & 393,1 \\
\hline $10^{\circ}$ & Porto da Pedra & 392,5 \\
\hline $11^{\circ}$ & Mocidade & 391,5 \\
\hline $12^{\circ}$ & Império Serrano & 390,7 \\
\hline
\end{tabular}

Dada esta configuração, o próximo passo é buscar alternativas utilizando outro método multicritério. Ainda que o esquema de notas atribuídas às escolas possa ser analisado sob uma ótica cardinal, optamos por fazer uma abordagem ordinal do problema. Dado também que o sistema atualmente utilizado é uma variação do sistema de Borda e os métodos de Condorcet e Copeland já foram aplicados a este problema em Gomes Júnior \& Gomes (2008), a matriz de decisão será avaliada segundo o método lexicográfico.
Além disso, uma outra razão para a utilização do método lexicográfico é a percepção de que os critérios não possuem a mesma importância. Por exemplo, o critério "Mestre-sala e porta bandeira”, que mobiliza cerca de seis pessoas (três pares) no desfile não deve ter o mesmo grau de importância que o critério "Alegorias e adereços", que pressupõe um trabalho muito maior por parte da escola de samba durante o ano e caracteriza muito mais o desfile do que a apresentação do casal de mestre-sala e porta-bandeira.

É esta percepção de assimetria entre os critérios que enseja a utilização de uma metodologia na qual os critérios não sejam avaliados como se todos eles possuíssem a mesma importância. $\mathrm{O}$ método lexicográfico considera esta assimetria ao ter como premissa o ordenamento dos critérios segundo a importância de cada um deles, o que torna interessante a sua utilização como metodologia alternativa

Um problema que se apresenta em relação à forma como os dados serão trabalhados é a complexidade da matriz de decisão: o problema dos desfiles das escolas de samba é um problema multicritério multidecisor. $\mathrm{Na}$ busca de uma simplificação para o problema, surgem duas possibilidades: transformá-lo em um problema monocritério multidecisor ou em um problema multicritério monodecisor. Para a primeira abordagem, poderíamos utilizar um critério que sintetizasse em si mesmo os outros nove que compóem a matriz de decisão. O critério "Conjunto", por exemplo, seria um critério adequado caso se optasse por utilizar esta alternativa. Para a segunda abordagem, 
teríamos que trabalhar com apenas um decisor em cada critério, em vez dos quatro decisores existentes para cada um deles. Opta-se, então, por não abdicar dos critérios de avaliação fornecidos, pois é sobre os mesmos que ocorrerá o ordenamento pelo método lexicográfico. Desta forma, escolhe-se a segunda alternativa, isto é, transformar o problema da avaliação das escolas de samba em um problema multicritério monodecisor. Portanto, a solução para a modelagem do problema envolve a transformação dos 40 decisores, ou seja, dos quatro decisores em cada um dos dez critérios, em um decisor único.

Isto pode ser feito de algumas maneiras. Uma delas é utilizarmos o decisor média, que será a média aritmética dos 4 jurados em cada um dos critérios. Outra opção é utilizarmos o decisor otimista, que será a maior nota fornecida pelos jurados em cada um dos critérios. Por analogia, é possível também utilizarmos o decisor pessimista, que será a nota mínima fornecida pelos jurados em cada um dos critérios.

Para obtermos uma melhor utilização do método lexicográfico, optamos por utilizar o decisor otimista. Este decisor provoca uma maior quantidade de empates entre as escolas de samba, principalmente empates com a nota máxima fornecida pelos jurados, a nota 10. Estes empates, à medida que ocorrem, maximizam a utilização dos critérios existentes.

O método lexicográfico se encerra a partir do momento em que não há mais empates entre as primeiras colocações. Portanto, se houver poucos empates, pode ser que a classificação final se dê utilizando uma quantidade pequena de critérios, de forma que uma grande quantidade de critérios terá sido computada sem serventia. Se utilizássemos o decisor média ou o decisor pessimista, por exemplo, um número bem menor de critérios seria necessário para definir a escola campeã do Carnaval.

O próximo passo é definir a estrutura lógica de ordenamento dos critérios. Para realizar esta ordenação, optou-se por organizar os critérios em grupos, ordená-los dentro dos grupos e, então, ordenar os grupos.

Desta forma, os critérios foram divididos em 4 grupos: critérios gerais, critérios visuais, critérios sonoros e critérios específicos. Os critérios gerais são aqueles nos quais a escola de samba é avaliada em todo o seu contexto. Os critérios visuais são aqueles nos quais a estética, em suas mais variadas formas, é avaliada. Os critérios sonoros são aqueles nos quais são avaliadas todas as questôes relativas à sonoridade da escola. Por fim, os critérios específicos são aqueles que avaliam elementos pontuais no desfile da escola de samba.

Os grupos, bem como cada um dos critérios dentro de seu grupo, foram ordenados tentando seguir a lógica do geral para o específico. Cabe ressaltar que o ordenamento dos critérios envolve uma grande carga de subjetividade por parte do decisor, de forma que estudos futuros podem propor outras alternativas de ordenação. Portanto, a ordem que será utilizada é tal como se segue:

Figura 4. Proposta de ordenamento de critérios

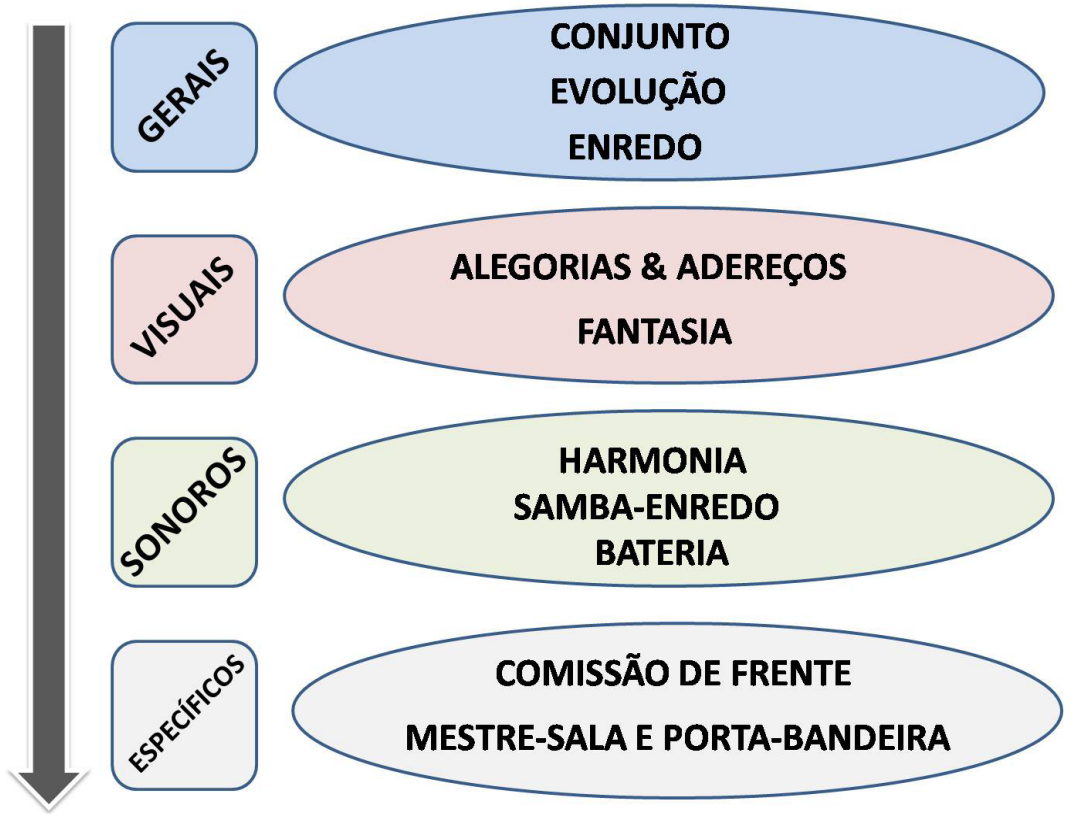


Para que possamos aplicar o método lexicográfico, precisamos dispor de uma nova matriz de decisão, que contemple os elementos necessários à realização do método. Portanto, a nova matriz de decisão, considerando o decisor otimista e a ordenação dos critérios segundo a Figura 4, será a seguinte:

Figura 5. Nova matriz de decisão utilizando o Decisor Otimista

\begin{tabular}{|l|c|c|c|c|c|c|c|c|c|c|}
\hline & CNJ & EV & ENR & A\&A & FAN & HAR & SE & BAT & CF & MS \\
\hline Império Serrano & 9,7 & 9,9 & 9,7 & 9,7 & 9,7 & 10 & 10 & 10 & 9,9 & 9,9 \\
\hline Grande Rio & 10 & 10 & 10 & 9,9 & 10 & 10 & 10 & 10 & 10 & 10 \\
\hline Vila Isabel & 10 & 10 & 10 & 10 & 10 & 10 & 9,9 & 10 & 10 & 10 \\
\hline Mocidade & 9,9 & 10 & 9,7 & 9,7 & 9,8 & 10 & 9,9 & 10 & 9,9 & 10 \\
\hline Beija-Flor & 10 & 10 & 9,9 & 10 & 10 & 10 & 10 & 10 & 10 & 10 \\
\hline Unidos da Tijuca & 10 & 10 & 9,8 & 9,7 & 10 & 10 & 10 & 10 & 10 & 10 \\
\hline Porto da Pedra & 9,8 & 9,8 & 9,8 & 9,9 & 9,9 & 9,9 & 9,8 & 10 & 9,9 & 10 \\
\hline Salgueiro & 10 & 10 & 10 & 10 & 10 & 10 & 10 & 10 & 10 & 10 \\
\hline Imperatriz & 9,9 & 10 & 10 & 9,9 & 10 & 10 & 10 & 10 & 10 & 10 \\
\hline Portela & 10 & 10 & 10 & 9,9 & 10 & 10 & 10 & 10 & 10 & 10 \\
\hline Mangueira & 10 & 10 & 10 & 9,9 & 10 & 10 & 10 & 10 & 10 & 10 \\
\hline Viradouro & 10 & 10 & 10 & 10 & 9,9 & 10 & 9,9 & 10 & 10 & 10 \\
\hline
\end{tabular}

Classificando esta matriz em ordem decrescente das preferências dos critérios ordenados, teremos o seguinte resultado:

Figura 6. Matriz de decisão ordenada para aplicação do método lexicográfico

\begin{tabular}{|l|c|c|c|c|c|c|c|c|c|c|}
\hline & CNJ & EV & ENR & A\&A & FAN & HAR & SE & BAT & CF & MS \\
\hline Salgueiro & 10 & 10 & 10 & 10 & 10 & 10 & 10 & 10 & 10 & 10 \\
\hline Vila Isabel & 10 & 10 & 10 & 10 & 10 & 10 & 9,9 & 10 & 10 & 10 \\
\hline Viradouro & 10 & 10 & 10 & 10 & 9,9 & 10 & 9,9 & 10 & 10 & 10 \\
\hline Portela & 10 & 10 & 10 & 9,9 & 10 & 10 & 10 & 10 & 10 & 10 \\
\hline Mangueira & 10 & 10 & 10 & 9,9 & 10 & 10 & 10 & 10 & 10 & 10 \\
\hline Grande Rio & 10 & 10 & 10 & 9,9 & 10 & 10 & 10 & 10 & 10 & 10 \\
\hline Beija-Flor & 10 & 10 & 9,9 & 10 & 10 & 10 & 10 & 10 & 10 & 10 \\
\hline Unidos da Tijuca & 10 & 10 & 9,8 & 9,7 & 10 & 10 & 10 & 10 & 10 & 10 \\
\hline Mocidade & 9,9 & 10 & 9,7 & 9,7 & 9,8 & 10 & 9,9 & 10 & 9,9 & 10 \\
\hline Imperatriz & 9,9 & 10 & 10 & 9,9 & 10 & 10 & 10 & 10 & 10 & 10 \\
\hline Porto da Pedra & 9,8 & 9,8 & 9,8 & 9,9 & 9,9 & 9,9 & 9,8 & 10 & 9,9 & 10 \\
\hline Império Serrano & 9,7 & 9,9 & 9,7 & 9,7 & 9,7 & 10 & 10 & 10 & 9,9 & 9,9 \\
\hline
\end{tabular}

Para facilitar a visualização dos dados, pode-se excluir os resultados daquelas escolas que não avançaram em algum critério, parando apenas no momento em que a escola obtém uma nota que a exclui da disputa (a nota aparece destacada em cinza na figura a seguir). Apresenta-se também a classificação das escolas de samba segundo o método lexicográfico. Portanto, teremos a matriz: 
Figura 7. Aplicação do método lexicográfico

\begin{tabular}{|l|l|c|c|c|c|c|c|c|c|c|c|}
\hline & & CNJ & EV & ENR & A\&A & FAN & HAR & SE & BAT & CF & MS \\
\hline $1^{\circ}$ & Salgueiro & 10 & 10 & 10 & 10 & 10 & 10 & 10 & 10 & 10 & 10 \\
\hline $2^{\circ}$ & Vila Isabel & 10 & 10 & 10 & 10 & 10 & 10 & 9,9 & & & \\
\hline $3^{\circ}$ & Viradouro & 10 & 10 & 10 & 10 & 9,9 & & & & & \\
\hline $4^{\circ}$ & Portela & 10 & 10 & 10 & 9,9 & & & & & & \\
\cline { 2 - 15 } & Mangueira & 10 & 10 & 10 & 9,9 & & & & & & \\
\cline { 2 - 15 } & Grande Rio & 10 & 10 & 10 & 9,9 & & & & & & \\
\hline $7^{\circ}$ & Beija-Flor & 10 & 10 & 9,9 & & & & & & & \\
\hline $8^{\circ}$ & Unidos da Tijuca & 10 & 10 & 9,8 & & & & & & & \\
\hline $9^{\circ}$ & Mocidade & 9,9 & & & & & & & & & \\
\hline & Imperatriz & 9,9 & & & & & & & & & \\
\hline $11^{\circ}$ & Porto da Pedra & 9,8 & & & & & & & & & \\
\hline $12^{\circ}$ & Império Serrano & 9,7 & & & & & & & & & \\
\hline
\end{tabular}

Cabe notar que o método lexicográfico permite a classificação dos elementos excluídos da disputa no caso de não haver empate entre as notas menores. Portanto, é possível dizer, segundo este método, que a Imperatriz Leopoldinense teve um desempenho melhor que a Porto da Pedra, mesmo que ambas as escolas tenham sido excluídas no primeiro critério. A comparação entre o resultado fornecido pelo método lexicográfico e a classificação dada pelo atual método de julgamento das escolas de samba pode ser vista na figura a seguir:

Figura 8. Comparação entre as classificações finais pelo método da LIESA e pelo método lexicográfico

\begin{tabular}{|c|c|c|}
\hline $\begin{array}{l}\bar{T} \\
\frac{+}{2}\end{array}$ & & ن. \\
\hline $1^{\circ}$ & Salgueiro & $1^{\circ}$ \\
\hline $2^{\circ}$ & Beija-Flor & $7^{\circ}$ \\
\hline $3^{\circ}$ & Portela & $4^{\circ}$ \\
\hline $4^{\circ}$ & Vila Isabel & $2^{\circ}$ \\
\hline $5^{\circ}$ & Grande Rio & $4^{\circ}$ \\
\hline $6^{\circ}$ & Mangueira & $4^{\circ}$ \\
\hline $7^{\circ}$ & Imperatriz & $9^{\circ}$ \\
\hline $8^{\circ}$ & Viradouro & $3^{\circ}$ \\
\hline $9^{\circ}$ & Unidos da Tijuca & $8^{\circ}$ \\
\hline $10^{\circ}$ & Porto da Pedra & $11^{\circ}$ \\
\hline $11^{\circ}$ & Mocidade & $9^{\circ}$ \\
\hline $12^{\circ}$ & Império Serrano & $12^{\circ}$ \\
\hline
\end{tabular}

Como pôde ser visto, os resultados fornecidos pelo método lexicográfico se aproximam bastante daqueles que foram percebidos quando da utilização do atual modelo de julgamento da LIESA.

Os resultados mais importantes, isto é, a primeira e a última escola de samba na classificação, respectivamente, a campeã do Carnaval 2009 e a escola que desfilará no Grupo de Acesso no ano seguinte, permanecem inalterados. Pelos dois métodos, a escola campeã continuaria sendo o Salgueiro e a última, a Império Serrano.

Percebe-se também que, exceto duas escolas, nenhuma das escolas teve uma variação na classificação maior do que duas posições. As únicas exceçōes foram a Beija-Flor e a Viradouro.

A Beija-Flor ficou em $2^{\circ}$ lugar no resultado fornecido pelo método atual e em $7^{\circ}$ segundo o método lexicográfico. Esta diferença se dá porque a escola obteve uma quantidade enorme de notas 10 dos jurados. Contudo, não recebeu nenhuma nota 10 no quesito Enredo, o terceiro mais importante segundo a metodologia alternativa utilizada. Isto fez com que o decisor otimista fornecesse à escola uma nota menor que 10 neste quesito $(9,9)$, o que a fez ser eliminada precocemente da disputa.

Este "poder de eliminação" que se dá aos critérios mais importantes pode provocar algumas distorçôes nos resultados e geralmente transmite a sensação de injustiça. Cruz \& Cova (2007) apon- 
tam com bastante clareza esta situação, citando o exemplo de um processo seletivo para uma vaga de emprego. Cruz \& Cova (2007) afirmam que, muitas vezes, bons candidatos são perdidos durante o processo seletivo porque não passam por um dos critérios em uma triagem, ainda que fossem muito bons nos critérios que estariam por vir. Este tipo de triagem e eliminação através de filtragem é muitas vezes percebida como uma inconveniência do método lexicográfico (Soares de Mello et al., 2008), apesar de ser uma de suas principais características.

A questão que envolve a Viradouro é um pouco mais complexa. A sua alta posição no método lexicográfico se deve a basicamente dois fatores. O primeiro fator tem a ver com o próprio método, no sentido de que a escola obteve desempenho máximo segundo o decisor otimista nos 4 critérios mais importantes, o que foi fundamental para que mantivesse uma boa posição, dado que outras escolas foram sendo eliminadas nestes critérios.

O outro fator não possui uma correlação direta com o uso do método lexicográfico, mas sim, com o decisor otimista. Do total de oito notas 10 conseguidas pela escola segundo o decisor otimista, seis foram conseguidas porque apenas um dos jurados deu nota máxima no critério. Isto faz com que muitas notas 10 que aparecem para escola Viradouro segundo o decisor otimista sejam "sustentadas" por apenas um dos jurados. Isto ocorre, por exemplo, no critério Conjunto, que é o critério mais importante. Apenas o $3^{\circ}$ Jurado deu nota 10 para a escola neste critério. Se mudássemos apenas a nota deste jurado, e supondo que ele a mudasse para a nota 9,9 , por exemplo, a escola cairia da $3^{a}$ posição para a $8^{a}$ posição no método lexicográfico, empatada com Mocidade e Imperatriz. Este resultado seria um resultado mais coerente com a posição obtida no método oficial de avaliação da LIESA.

\section{CONCLUSÃO}

Conclui-se que, para o caso estudado. o método lexicográfico proporcionou resultados factíveis e verossímeis, mesmo em se tratando de um caso que envolvia uma grande quantidade de critérios, como o caso dos desfiles das escolas de samba do Carnaval do Rio de Janeiro no ano de 2009.
Isto se deve, em parte, à grande quantidade de notas 10 fornecidas pelos jurados na avaliação das escolas de samba. Unindo-se esta grande quantidade de notas máximas ao uso do decisor otimista, percebe-se uma grande quantidade de empates, o que faz com que sejam necessários muitos critérios para se chegar à decisão final.

Contudo, sugere-se que não se utilize o método lexicográfico como o método a ser utilizado na avaliação das escolas de samba. Tal qual a conclusão chegada por Gomes Júnior e Gomes (2008), o método atualmente utilizado já possui uma certa tradição e apresenta fácil entendimento por parte do público. Não há necessidade de mudança, portanto, já que os resultados apresentados pelo método lexicográfico muito se assemelham aos resultados do método oficial de avaliação da LIESA.

Mantém-se a necessidade, no entanto, de se continuarem as pesquisas quanto aos métodos alternativos para a avaliação das escolas de samba, em busca de alguma melhoria neste processo de avaliação.

Gomes Júnior e Gomes (2008) sugerem que sejam realizados estudos utilizando-se os métodos da família ELECTRE. Sugere-se, adicionalmente, a realização de estudos que considerem outros métodos multicritério de apoio à decisão, tais como AHP, MACBETH, MAUT, PROMETHEE, dentre outros.

\section{BIBLIOGRAFIA}

(1) ABDELLAOUI, M.; GONZALES, C. (2010) Multiattribute Utility Theory. In: Decision-making Process: Concepts and Methods. Org.: BOUYSSOU D.; DUBOIS, D; PIRLOT, M.; PRADE, H. ISTE, London.

(2) ARAÚJO, Hiram. (2009). Carnaval. Disponível em: http://liesa.globo.com/por/08historiadocarnaval/08-historiadocarnaval_principal.htm Acesso em: 17/06/2009

(3) BANA e COSTA, C.A.; VANSNICK, J.C. (1995). Uma nova abordagem ao problema da construção de uma função de valor cardinal: MACBETH. Investigação Operacional, v. 15, p. 15-35.

(4) BARBA-ROMERO, S.; POMEROL, J.C. (1997). Decisiones multicriterio: fundamentos 
teóricos e utilización práctica. Servicio de Publicaciones de la Universidad de Alcalá, Alcalá.

(5) BRANS, J. P.; VINCKE, P. H. (1985) A preference ranking organization method, the PROMETHEE method for MCDM. Management Science, v.31, pp. 647-656.

(6) CARVALHO, A. P. O. (2008). Metodologia Multi-Critério para Análise da Qualidade Acústica em Igrejas, Proceedings of the ACUSTICA 2008 - V Congresso Ibérico de Acústica, Coimbra.

(7) CRUZ, E. P.; COVA, C. J. G. (2007). Teoria das decisóes: um estudo do método lexicográfico. Revista Pensamento Contemporâneo em Administração, v.1. p. 35-45

(8) DIAS, L. M. C.; ALMEIDA, L. M. A. T.; CLÍMACO, J. (1996). Apoio multicritério à decisão. Universidade de Coimbra, Coimbra.

(9) DIAS, L. M. C; CLÍMACO, J. (2000) Additive aggregation with variable interdependent parameters: The VIP analysis software. Journal of the Operational Research Society, v. 51, n. 9, p. 1070-1082.

(10) FIGUEIRA, J.; MOUSSEAU, V.; ROY, B. (2005) Electre Methods. In: Multiple Criteria Decision Analysis: State of the Art Surveys. International Series in Operations Research \& Management Science, v. 78, III, pp. 133-153.

(11) GOMES JÚNIOR, S. F. \& GOMES, A. R. (2008). Análise dos resultados dos desfiles de carnaval do Rio de Janeiro com emprego dos métodos ordinais multicritério. XI Simpósio de Pesquisa Operacional e Logística da Marinha. Rio de Janeiro: Agosto de 2008.

(12) GOMES JÚNIOR, S. F., SOARES DE MELLO, J. C. C. B; SOARES DE MELLO, M. H. C. (2008). Utilização do método de Copeland para a avaliação dos pólos regionais do Cederj. Rio's International Journal on Sciences of Industrial and Systems Engineering and Management, v.2.

(13) KENDALL, G.; KNUST, S.; RIBEIRO, C. C.; URRUTIA, S. (2010) Scheduling in sports:
An annotated bibliography. Computers \& Operations Research, v. 37, n.1, pp. 1-19.

(14) LEAL, C. P. (2007). Porto Alegre carnavalesca: o entrudo através do olhar imagético. História, imagem e narrativas, no5, ano 3, setembro/2007.

(15) LIESA. (2009). Liga Independente das Escolas de Samba. Disponível em: http://liesa. globo.com Acesso em: 17/06/2009

(16) OLIVEIRA NETO, J. L. (2008). Aplicação de modelo multicritério em apoio à seleção de empresas de base tecnológica candidatas à incubação: uma abordagem a partir da "capacidade empreendedora" com uso da metodologia e do software Macbeth. Dissertação de Mestrado, Unifor, Fortaleza.

(17) OPRICOVIC, S.; TZENG, G. (2004) Compromise solution by MCDM methods: A comparative analysis of VIKOR and TOPSIS. European Journal of Operational Research, v. 156, n.2, pp. 445-455.

(18) ROY, B.; BOUYSSOU, D. (1993). Aide multicritère à la décision: méthods et cas. Economica, Paris. 695p.

(19) SAATY, T.L. (1980). The Analytic Hierarchy Process. McGraw-Hill, New York.

(20) SCARF, P.; YUSOF, M. M.; BILBAO, M. (2009) A numerical study of designs for sporting contests. European Journal of Operational Research, v.198, n.1, pp. 190-198.

(21) SOARES DE MELLO, J. C. C. B; GOMES JÚNIOR, S. F; LACERDA, F. G. (2008). Aplicação de método multicritério otimista para avaliação de desempenho e ocorrência de home advantage em esportes: o caso dos jogos panamericanos. XXVIII Encontro Nacional de Engenharia de Produção. Rio de Janeiro: outubro de 2008.

(22) SOARES DE MELLO, J.C.C.B.; GOMES, L.F.A.M.; GOMES, E.G., et al. (2005). Use of ordinal multi-criteria methods in the analysis of the Formula 1 World Championship. Cadernos EBAPE.BR (FGV), Rio de Janeiro, v. 3, n. 2, p. 3. 
(23) SOARES DE MELLO, J.C.C.B., GOMES., E.G., LETA, F.R., PESSOLANI, R.B.V. (2003). Conceitos básicos do apoio multicritério à decisão e sua aplicação no projeto aerodesign. Engevista, v. 5, n. 8, p. 22-35.

(24) SOARES DE MELLO, J.C.C.B. ; GOMES, E.G.; LINS, M.P.E. (2001). Uso da pesquisa operacional em esportes: o caso das olimpíadas. Boletim da SOBRAPO, v. 19, p. 5-6.
(25) VALLADARES, G. S.; GOMES, E. G.; SOARES DE MELLO, J. C. C. B. et al. (2008). Análise dos componentes principais e métodos multicritério ordinais no estudo de organossolos e solos afins. Revista Brasileira de Ciências do Solo, v.32, n.1. 